\title{
Effect of newly refined hypocenter locations on the seismic activity recorded during the 2016 Kumamoto Earthquake sequence
}

\author{
Tomoko Elizabeth Yano* and Makoto Matsubara
}

\begin{abstract}
We present the results of relocating 17,544 hypocenters determined from data recorded during the 2016 Kumamoto Earthquake sequence, during the interval between April 14, 2016, and August 31, 2016. For this, we used a doubledifference relocation method to constrain high-resolution hypocenter locations by cross-correlation differential times as well as the NIED Hi-net catalog differential times. The sequence included two large events (on 14 April: $M_{\text {JMA }} 6.5$ and on 16 April: $M_{\mathrm{JMA}} 7.3$ ) that occurred in a complicated region where the Hinagu and Futagawa faults meet. By comparing these high-resolution earthquake locations in three different periods [(P1) between 2001 and 2012; (P2) between $M_{\mathrm{JMA}} 6.5$ and $M_{\mathrm{JMA}} 7.3$; and (P3) between $M_{\mathrm{JMA}} 7.3$ and August 31, 2016], we present the significant seismicity after the mainshock relative to the background seismicity. Events during the Kumamoto Earthquake sequence occurred generally within the same sites of known faults and background seismicity. For an example, the seismicity during period P2 formed a sharp linear shape along the northern part of the Hinagu fault for about $20 \mathrm{~km}$. A series of linear seismicity events occurred during period P3 along the Futagawa fault to the east (for about $28 \mathrm{~km}$ ), in the northern part of the Aso caldera, and in the Oita region around the Beppu-Haneyama fault zone. These events also extended to the midand southern parts of the Hinagu fault zone and were shaped only after the M7.3 event. Moreover, high-resolution hypocenter locations also allowed us to identify some clusters of events that occurred in regions where background seismicity has not been confirmed. For instance, activity on the northwestern edge of the Aso caldera and in small areas within the Beppu-Haneyama fault zone became apparent with new seismic activity. We also demonstrate herein the absence of seismicity between the northeast extension of the Futagawa fault zone and the Aso caldera region, which became clearly shown after the M7.3 event. This low-seismicity region is located at the boundary of the low- and high-velocity structures and different focal mechanisms, but is also close to the maximum slip area of the M7.3 event.
\end{abstract}

Keywords: The 2016 Kumamoto Earthquake, Double-difference method, Active fault zone, The Beppu-Shimabara graben

\section{Introduction/background}

During the 2016 Kumamoto Earthquake sequence, many crustal earthquakes occurred in the KumamotoOita region, central Kyushu, southwestern Japan. The 2016 Kumamoto Earthquake sequence included the two

${ }^{*}$ Correspondence: tomoyano@gmail.com

National Research Institute for Earth Science and Disaster Resilience, Tsukuba, Ibaraki, Japan largest earthquakes, $M 6.5$ (magnitude $6.5: M_{\mathrm{JMA}}$, hereafter referred to as " $M$ "; thus $M 6.5$ ) and $M 7.3$, which occurred on April 14, 2016, and on April 16, 2016, respectively (Fig. 1 ). The largest one, $M 7.3$, recorded the largest ground acceleration of 1580 gal at Mashiki town.

The locations of these two largest events were at the junction of the Hinagu and Futagawa fault zones, and a wide area of aftershocks occurred along the major tectonic line (the Beppu-Shimabara graben) running from 


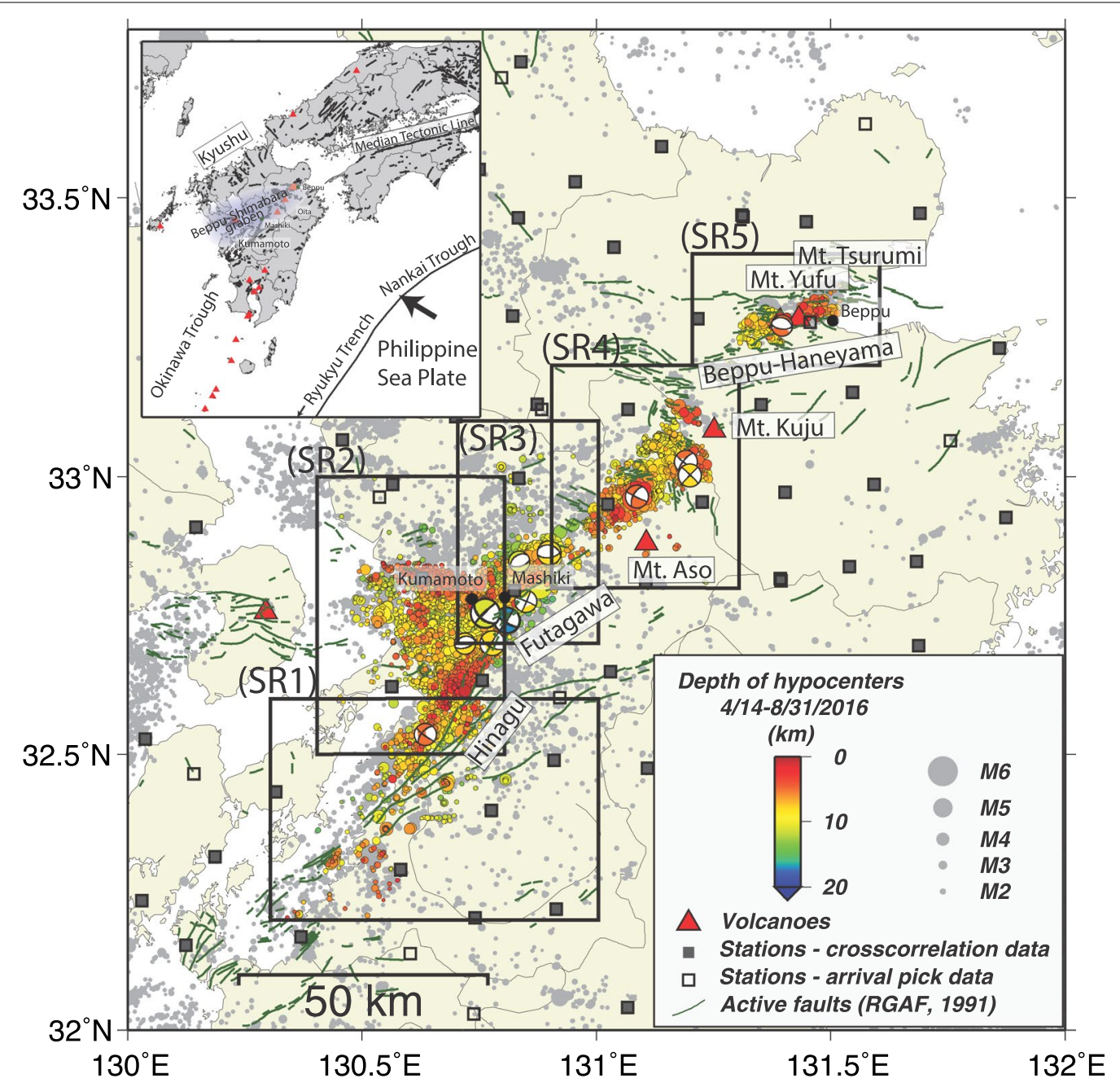

Fig. 1 Map of epicentral distribution relocated using hypoDD and station distribution: gray and colored circles denote the seismicity during 2000-2012 and April 14, 2016-August 31, 2016, respectively. Because the completeness of magnitude for the entire study region went up to a maximum of $M_{\text {Hi-net }} 1.0$ during the 2016 Kumamoto Earthquake sequence (Additional file 1: Figure S4), only events with $M_{\text {Hi-net }} 1.0$ or greater were included in this paper and figures. The F-net CMT solution is indicated in this figure. Active faults are indicated as dark green lines (Research Group for Active Faults of Japan (RGAFJ) 1991)

Beppu in the northeast to Shimabara in the northwest of Kyushu Island between the Median Tectonic Line and the Okinawa Trough. Large active volcanoes, such as Mt. Aso and Kuju, are located within this graben, and major active faults, such as the Beppu-Haneyama, Futagawa, and Hinagu faults, are located in or along the edges of this graben.

There have been several major historical events within the same region affected by the 2016 Kumamoto Earthquake sequence. Among these are the $M 6.0 \pm 1 / 4$ event in 1619 along the Hinagu fault (Yatsushiro-Minamata, the southern section of the Hinagu fault); the 1889 M6.3 Kumamoto Earthquake in the vicinity of the 2016 Kumamoto Earthquake; the 1894 M6.3 and the 1895 M6.3 events that occurred at the outer edge of the Aso caldera; and the 1596 M7.0 Keicho-Bungo earthquake in the Beppu region (The Headquarters for Earthquake Research Promotion (HERP) 2013). The Eurasian (EUR)-Philippine Sea (PHS) plate subduction zone is located offshore to the east of Kyushu Island where the PHS plate subducts northwestward under the EUR plate, the southwestern Japan Arc and the Ryukyu Arc at a rate of about $50 \mathrm{~mm} /$ year (Seno et al. 1993). It has been argued that one of the major tectonic events (an oblique subduction of the PHS plate) re-activated the Median Tectonic Line (MTL) as a dextral detachment fault (Fitch 1972; Matsuda 1973). Another major tectonic event is from the Beppu Bay through mid-Kyushu Island, where the tectonic activity shifts from simple strike-slip movement to normal domain (Terakawa and Matsu 2010; Matsumoto 
et al. 2015). In fact, normal-type events with $P$ axis of a NS orientation are also dominated during the 2016 Kumamoto Earthquake in this location as shown in Fig. 1. This tectonic shift can be explained by subduction beneath the Ryukyu Arc giving rise to back-arc spreading in the Okinawa Trough. This tectonic event caused the crustal rotation of southern Kyushu (e.g., Kamata and Kodama 1994). Therefore, the dextral fault movement, coupled with the pull-apart geometry between the Ryukyu graben, explains the east-to-northeast-trending Beppu-Shimabara graben extending on a NS orientation. The graben is cut by a number of east-west-trending faults, including the Futagawa and Beppu-Haneyama fault zones, dominated by the strike-slip and normal faults. The Hinagu fault zone is branched from the Futagawa fault zone to the southwest.

The epicentral region of the 2016 Kumamoto Earthquake is complex, under $\mathrm{N}-\mathrm{S}$ tensional stress, and both strike-slip and normal-faulting earthquakes have occurred in the spatial vicinity of the April 14, 2016, and April 16, 2016, events. After the M7.3 event on April 16, 2016, the seismicity spreads over a broad area, such as the Aso area and Beppu-Haneyama fault zone located in the eastern part of the Beppu-Shimabara graben.

In this paper, we focus on the crustal earthquake $\left(M_{\mathrm{Hi}-}\right.$ net $\geqq 1.0$, depth to $20 \mathrm{~km}$ ) particularly responsible for four main affected areas: the Hinagu fault zone, the Futagawa fault zone, the Aso area, and the Beppu-Haneyama fault zone of the 2016 Kumamoto Earthquake. Since these affected areas are sandwiched between the major tectonics regions of the Median Tectonic Line and Okinawa Trough, it is important to understand the precise hypocenter locations and associated seismicity to enable further studies such as tectonics and precise earthquake hazard assessment at local and community scale.

\section{Data and methods}

We applied the double-difference hypocenter location (hypoDD; Waldhauser and Ellsworth 2000), by adopting cross-correlation of waveforms as well as the ordinal differential P- and S-wave arrival time, to events $(M \geqq 0.0)$ that occurred during for about four months between April 14, 2016, and August 31, 2016. The datasets relate to the events of the 2016 Kumamoto Earthquake sequence including the largest $M 7.3$ event that followed the second largest M6.5 event, and their aftershocks. Only these of events with eight or more manual phase picks were processed for relocations.

A total of 17,544 events within five different subregions: (SR1) south of Kumamoto city, (SR2) central Kumamoto prefecture, (SR3) Mashiki town region (a part of Kumamoto prefecture), (SR4) the Aso region, and (SR5) Oita region, are shown in Fig. 1. These five subregions overlap neighboring subregions within a maximum of $0.1^{\circ}$. In order to understand the local and detailed characteristics of each active fault, a relocation procedure was made for each subregion independently.

In addition to the differential travel time derived from $\mathrm{P}$ - and $\mathrm{S}$-wave arrival times, we incorporated the differential travel times derived from cross-correlation of the waveform data (100 samples/s). These data were obtained from stations of the high-sensitivity seismograph network (Hi-net) operated by the National Research Institute for Earth Science and Disaster Resilience (NIED) (Okada et al. 2004; Obara and Ito 2005); seismic stations operated by Japan Meteorological Agency (JMA), Kyushu University, and Kagoshima University (Fig. 1). Before calculating a differential travel time using cross-correlation, we applied a Butterworth-type band-pass filter to each waveform, specifying a low-frequency cutoff of $3 \mathrm{~Hz}$ and a high-frequency cutoff of $20 \mathrm{~Hz}$, with a filter order of two for our waveforms. Details about which how to derive these waveforms into differential travel time are explained in the existing study of the JUICE project (Yano et al. 2017). The relocation regions (such as SR1-SR5 shown in Fig. 1) were chosen based on the locations of corresponding active faults and affected areas during the Kumamoto Earthquake sequence. We performed the relocation computation using the hypoDD algorithm (Waldhauser and Ellsworth 2000) with a 1D-layered P-wave velocity model (Ukawa et al. 1984). The S-wave velocity model was estimated by scaling the P-wave velocity model by a factor of $1.73\left(V_{\mathrm{p}} / V_{\mathrm{s}}\right)$ representing a shallow depth $(\sim 10-20 \mathrm{~km})$ according to Ukawa et al. (1984). Weighting/reweighting parameters are given in Additional file 2: Table S1.

\section{Results}

Double-difference relocation method is a highly tested method by which to refine hypocenter locations to higher resolution and confined clusters. We present the results of relocation in the five subregions (Fig. 1) focusing on the known faults such as (SR1) the Hinagu fault zone, (SR2) the junction of the Hinagu and Futagawa fault zones, (SR3) the Futagawa fault zone, (SR4) the Aso region, and (SR5) the Beppu-Haneyama fault zone. These five subregions contained 2011, 10,574, 5411, 3690, and 629 relocated events, respectively. The total number of relocated events was 22,315, which includes some duplicate events because subregions overlapped. The RMS residual [ms (\%)], represented by the largest cluster, for each subregion (SR1-SR5) was 69 (47.9), 68 (43.5), 69 (39.1), 67 (34.2), and 76 (38.9), respectively. A number of unique events were 17,544 . We simply took a unique event after sorting the results since it does not affect our 
conclusion because these RMS residuals are smaller than the scale of our scope in this study.

Taking advantage of the high resolution of relative hypocenter locations, we showed our relocation results by focusing on their seismicity along the four well-known active areas: Hinagu fault zone, Futagawa fault zone, the Aso caldera, and the Beppu-Haneyama fault zone. We compared the seismicity in three different periods: (P1) in which seismicity regularly occurred according to the relocated hypocenter catalog of 2000-2012 compiled during the JUICE project (Yano et al. 2017: total events in our study region were 45,011) shown in Figs. 1, 3, and 4; (P2) during $M 6.5-M 7.3$ events in red dots shown in Figs. 1, 2, 3, and 4; and (P3) from the M7.3 event to August 31, 2016, in blue dots shown in Figs. 1, 2, 3, and 4. In our paper, we only show events with $M 1.0$ or larger

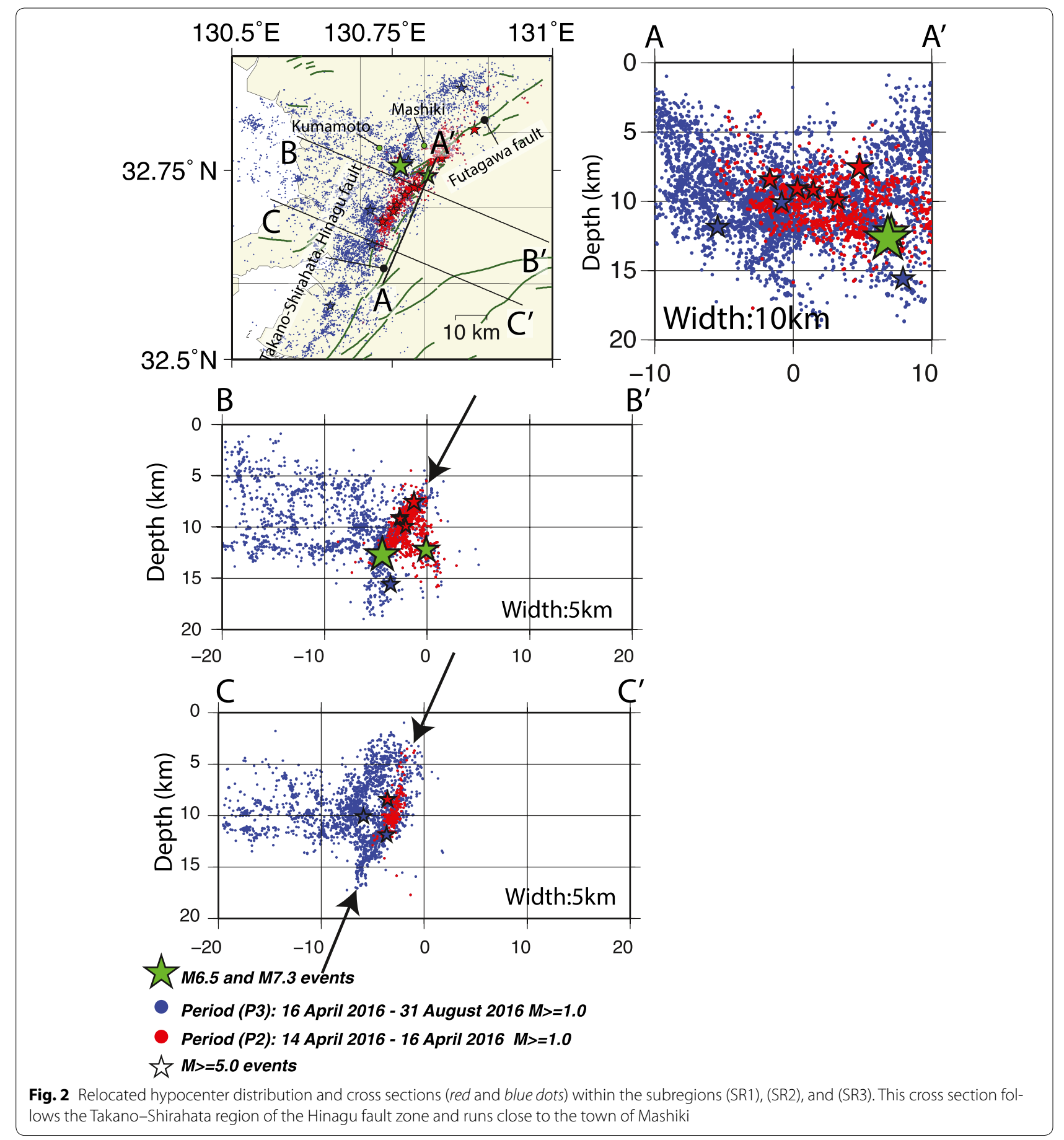




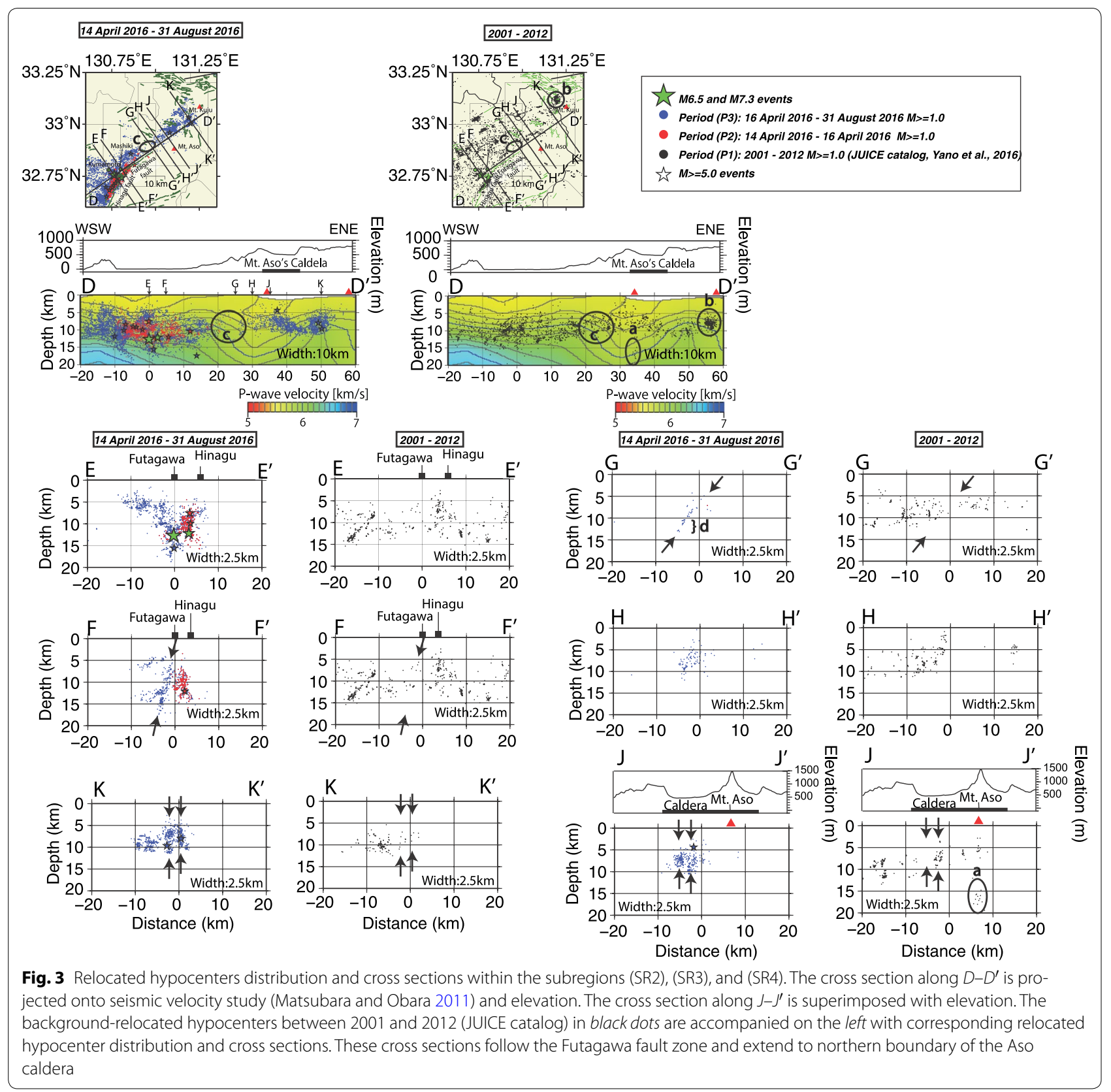

because the completeness of magnitude during the Kumamoto Earthquake sequence went up to minimum of M1.0 or greater.

\section{Hinagu fault zone}

In Fig. 2, our result shows that the hypocenter of the M7.3 event was about the same depth as the M6.5 event. The events during the period P3 occurred about $5 \mathrm{~km}$ deeper than the seismicity in the period P2. The robustness of this difference in depth due to this relocation result was tested by relocating 100 times with 100 different velocity models to estimate uncertainty. The result of this test indicates that a $5-\mathrm{km}$ difference in depth is enough to be significant shown in Additional file 3: Figure S2.

The linear seismicity, with dip angle of about $70^{\circ}$ to the northwest, is clearly seen at the cross section (arrows in cross sections along the lines $\mathrm{B}-\mathrm{B}^{\prime}$ and $\mathrm{C}-\mathrm{C}^{\prime}$ in Fig. 2) running along the Hinagu fault in the Takano-Shirahata region. This location and dip angle agree with the reported characteristics of the Hinagu fault (HERP 2013), "high-angle dipping," and with the NIED F-net moment tensor (CMT) solution of the M6.5 event with dip angle of $74^{\circ}$. Therefore, the Hinagu fault is most likely 
14 April 2016 - 31 August 2016
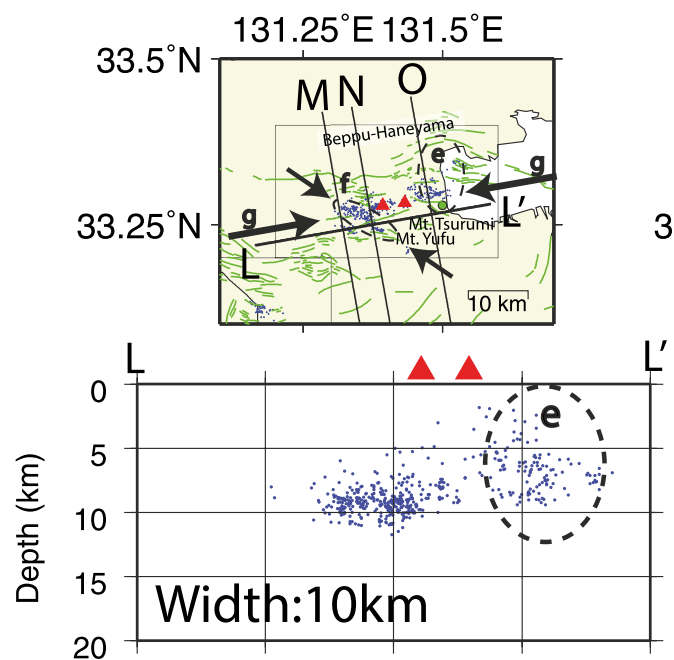

M
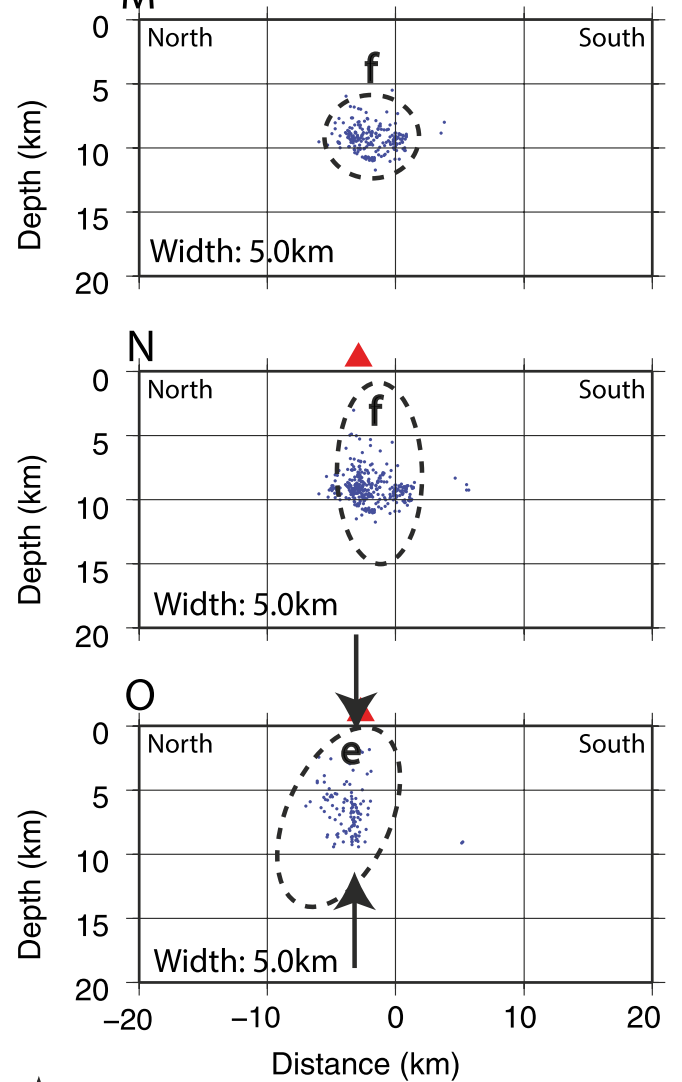

Distance $(\mathrm{km})$
$2001-2012$

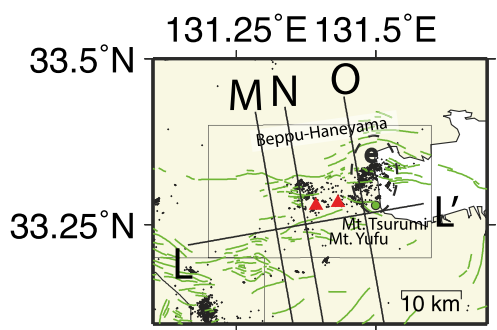

$\mathrm{L}^{\prime}$

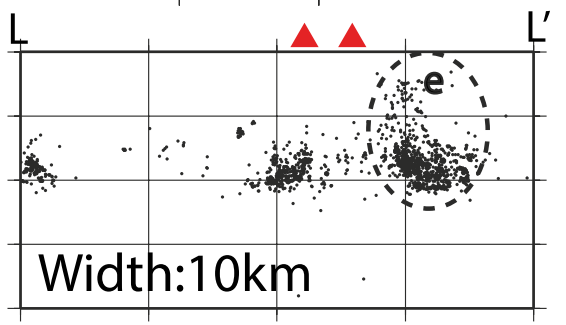

M

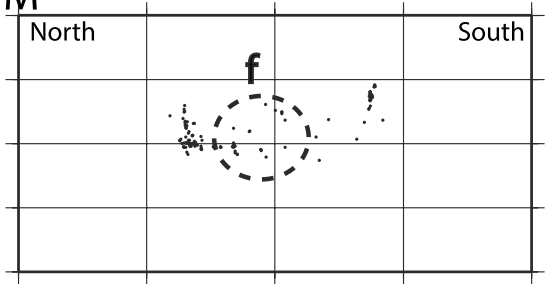

$\mathrm{N}$

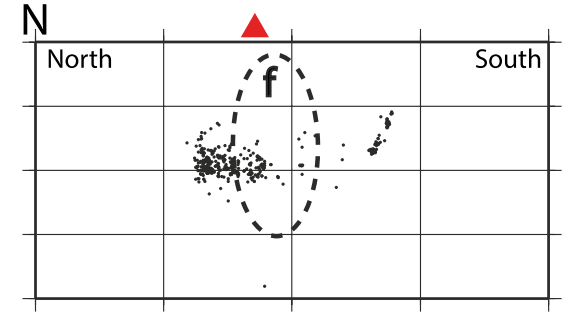

O

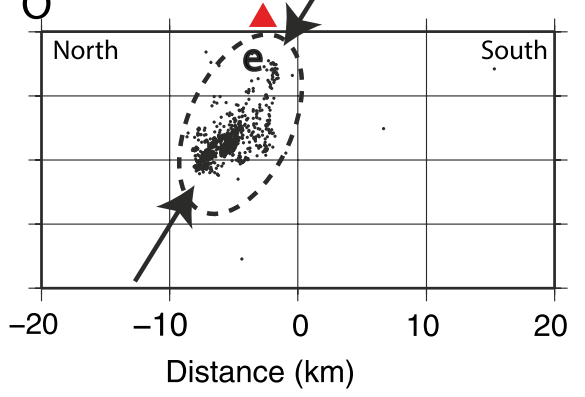

M6.5 and M7.3 events

Period (P3): 16 April 2016 - 31 August 2016 M>=1.0

Period (P2): 14 April 2016 - 16 April 2016 M>=1.0

Period (P1): 2000 - 2012 M>=1.0 (JUICE catalog, Yano et al., 2016)

is $M>=5.0$ events

Fig. 4 Relocated hypocenters distribution and cross sections accompany the relocated hypocenter of 2001-2012 in the right column within the subregion (SR5). This cross section follows the Beppu-Haneyama fault zone 
responsible for this linear seismicity during the period P2 including the $M 6.5$ event.

An overall characteristic of the seismic activity in the Takano-Shirahata section shown in cross section along the line $\mathrm{A}-\mathrm{A}^{\prime}$ in Fig. 2 is that events that occurred during period P3 were over a broader range and at deeper depth than the events during period P2. It is noteworthy that the nucleation point of the $M 7.3$ event can be seen at the depth extending from the Hinagu fault trace (line $\left.B-B^{\prime}\right)$. However, the dip angle of the M7.3 event does not agree with the dip angle of the Hinagu fault. According to the F-net CMT solution, the dip angle of the $M 7.3$ event was a $53^{\circ}$.

\section{Futagawa fault zone}

After the largest M7.3 event on April 16, 2016, a substantial number of events occurred along and surrounding the Futagawa fault zone and its surroundings (Fig. 3). As far as the background seismicity in 2001-2012 for $M \geqq 1.0$ (shown in black dots on map and cross section along $\mathrm{D}-\mathrm{D}^{\prime}$ in Fig. 3), linear seismicity can be seen along the Hinagu and Futagawa fault trace with maximum depth about $15 \mathrm{~km}$. Events during the Kumamoto Earthquake sequence in the epicentral region show profound seismicity, activity which penetrated deeper depth (to $20 \mathrm{~km}$ ) than the background seismicity (see the cross section along the lines $\mathrm{E}-\mathrm{E}^{\prime}$ and $\mathrm{F}-\mathrm{F}^{\prime}$ in Fig. 3). We performed the same test as "Hinagu fault zone" section on the background seismicity. The test indicated that a $5-\mathrm{km}$ difference in depth is large enough to be significant shown in Additional file 3: Figure S2.

The dip angle is difficult to estimate from the seismicity near the epicentral region, because it is distributed over a broad range due to its occurrence at the margin of two faults (the Hinagu and Futagawa faults; see line $\mathrm{E}-\mathrm{E}^{\prime}$ in Fig. 3). However, we determined a dip angle of about NW75 (arrows in cross section F-F') from a sharper and confined linear distribution seen slightly away from the epicentral region. This linear trace corresponds to the Futagawa fault because it agrees with its dip angle, "NW dipping" (HERP 2016), as well as with the fault location.

\section{Aso mountain region}

After the 2016 Kumamoto Earthquake, the hypocenter distribution during the Kumamoto Earthquake sequence defined a low-seismicity region between the Futagawa fault zone and the Aso region. The area (marked "c" in Fig. 3) had less seismicity in comparison with its surroundings and is located at the outer rim of the Aso caldera. This pattern was clear enough to look like it isolates the seismicity of the outer rim of the Aso caldera from the seismicity of the Futagawa fault zone. It is noteworthy that this region without seismicity is robust because its size is about $5 \mathrm{~km}$, which is larger than the distance corresponding to the RMS residual (67 ms) for this region.

According to the background seismicity shown in black dots in Fig. 3, an area around the Aso caldera and Mt. Kuju has been moderately active. Their seismicity forms vertical to northward dipping as indicated by arrows in the cross sections along the lines $\mathrm{G}-\mathrm{G}^{\prime}$, $\mathrm{H}-\mathrm{H}^{\prime}, \mathrm{J}-\mathrm{J}^{\prime}$, and $\mathrm{K}-\mathrm{K}^{\prime}$. In addition, some low-frequency volcanic events occurred at depth deeper than $15 \mathrm{~km}$ (marked "a" in Fig. 3 along the line D-D'), and a large cluster of hypocenters occurred underneath the Kuju volcano at $5-10 \mathrm{~km}$ depth (marked "b" in Fig. 3 along the line $\left.\mathrm{D}-\mathrm{D}^{\prime}\right)$. During the Kumamoto Earthquake sequence, vertical to northward dipping activity is apparent. In particular, the seismicity with vertical dipping shown in the cross section $\mathrm{K}-\mathrm{K}^{\prime}$ was accompanied by two relatively large aftershocks $(M \geq 5.0)$.

\section{Beppu-Haneyama fault zone}

The Beppu-Haneyama fault zone belongs to a part of the eastern tip of the Beppu-Shimabara graben and to active volcanoes such as Mt. Yufu and Mt. Tsurumi (Figs. 1, 4). Many fault traces in this zone are short from less than $5 \mathrm{~km}$, with individual NW-SE trending, in vertical to near vertical dipping. A band of these small faults lies along the NE-SW trend and makes up the BeppuHaneyama fault zone.

The background seismicity indicated in Fig. 4 with black dots shows a large cluster of hypocenters in region "e." The cluster in "e" contains a hypocenter for the M5.0 event on June 6,2007 . This cluster was located at the eastern tip of the Beppu-Haneyama fault zone dipping to the north, as shown in arrows on cross section "O" in Fig. 4. A part of the cluster in "e" was active during the 2016 Kumamoto Earthquake sequence with vertical dipping shown by arrows. This was a different dipping angle from that of the background seismicity.

\section{Discussion}

\section{Absence of seismicity beneath the northwestern part} of the Aso caldera

According to the background seismicity, a part of the Aso caldera, as well as the northern end of the Futagawa fault zone, has been a moderately active seismic area (see cross section D-D' of the seismicity between 2001 and 2012 in Fig. 3). Because of this moderate seismicity, the boundary between these two zones (the Aso area and Futagawa fault zone) cannot be clearly identified using the previous catalog alone. After the 2016 Kumamoto Earthquake, the southern part of the Aso caldera was clearly isolated from Futagawa fault zone by a region without seismicity (marked as " $\mathrm{c}$ " in the cross section along the line D-D' in Fig. 3). We discuss this low-seismicity zone just after the 
2016 Kumamoto Earthquake in spite of the active seismic zones around here.

This low-seismicity region located at the outer rim of the Aso caldera has a high gradient in P-wave velocity structure according to the P-wave velocity model (Matsubara and Obara 2011). The F-net CMTs (Fig. 1) of the southwestern and northeastern side (bounded by the low-seismicity region) are different type. The normal type of CMT solutions is dominated in southwestern side, while strike-slip type is dominated in the northeastern side of the low-seismicity area. The source inversion result shows that the maximum slip area of the M7.3 event was close to this location (Kubo et al. 2016). Moreover, there are segmentations found at this low-seismicity region by the analysis of gravity gradient tensors (Matsumoto et al. 2016). This is interesting if this segmentation is responsible for this low-seismicity phenomenon during the Kumamoto Earthquake sequence.

Although there is structural anomaly found in tomography result, change in type of focal mechanism, and segmentation exist at this particular location, we still cannot reject the idea that the low seismicity may not be due to the structural anomaly. This is because there has been moderate background activity for over 10 years, which could not recognize a significant spatial anomaly in seismic density from surroundings before the mainshock.

To show (1) how low the seismicity at the region relates to the areas adjacent to it and (2) how significant this lowseismicity region after the mainshock, we quantify using the seismic density for three areas including the west (W) and east $(E)$ sides of the low-seismicity regions shown in Additional file 4: Figure S5. For (1), we show that the ratios of seismic density defined by the ratio of events $(M \geq 2.0)$ for the period P1 and for the period P3 at the region to that of within the west and east areas were 0.22 (W), 0.7 (E) for P1, and $0.06(\mathrm{~W}), 0.1$ (E) for P3. These lower values, which are one order less than the period P1, imply that the region has extremely low seismicity in comparison with the areas adjacent to it. For (2), the ratios of seismic density defined by the ration of events $(M \geq 2.0)$ for the period P1 to that of for the period P3 in three regions were 269.5 (W), 585 (E), and 85.7 (low-seismicity region). These values imply that the seismic densities after the mainshock were hundreds of time denser than that of before the mainshock except at the low-seismicity region. In other words, these regions with large ratio, west and east, made the seismicity between them became significantly low after the mainshock.

If the reason for the low-seismicity phenomenon is not due to the structural anomaly, large rupturing during the co-seismic period of the Kumamoto Earthquake at this area can be one of candidates for the cause of this low-seismicity region being significant only after the mainshock.

\section{New seismic area after the Kumamoto Earthquake}

Most events during the Kumamoto Earthquake sequence can be found in the areas where earthquakes have regularly occurred. On the other hand, some clusters of events were also seen in regions where the seismicity has not been confirmed at least for 12 years from 2001 to 2012.

We discuss this new seismicity by focusing on three regions, the northern edge of the Aso caldera and the Oita region along the Beppu-Haneyama fault zone (mentioned in "Northern edge of the Aso caldera" and "Beppu-Haneyama fault zone" sections, respectively).

\section{Northern edge of the Aso caldera}

In Fig. 3 on the cross section along the line $G-G^{\prime}$, linear seismicity dipping northwest about $70^{\circ}$ penetrates deeper than $10 \mathrm{~km}$ (marked as "d" on cross section of line $\mathrm{G}-\mathrm{G}^{\prime}$ in Fig. 3), while the background seismicity at the same depth had been relatively quiet in the past. Moreover, the dipping angle of this linear seismicity (arrows in the cross section along the line $\mathrm{G}-\mathrm{G}^{\prime}$ ) changes to vertical dipping (arrows in $\mathrm{J}^{-} \mathrm{J}^{\prime}$ ) as being away from the low-seismicity region "c."

There are total of three events $(M \geq 5)$ in this area during the period P3 and their F-net CMT solutions gave strike-slip types (Fig. 1). P-wave velocity structure beneath the location between lines $G-G^{\prime}$ and $K-K^{\prime}$ has thick high-velocity layer (Matsubara and Obara 2011). In fact, lower Bouguer anomaly distribution was found in this range, which is responsible to the Aso volcano being filled with relatively light Quaternary volcanic and pyroclastic rocks (Matsumoto et al. 2016). Seismic activity at the intracaldera faults of the Long Valley presents similar futures (Prejean 2002) such as they include a series of strike-slip faults beneath the caldera's moat and near vertical dipping angles. The pattern of seismicity around this area is one of the common features at the intercaldera seismicity, which became active after the mainshock.

Another feature to worth mention is a linear pattern of seismicity during the Kumamoto Earthquake sequence (shown in the cross section $\mathrm{K}-\mathrm{K}^{\prime}$ in Fig. 3) with vertical dipping in the northeast part of the Aso area. These hypocenters accompanied with two events $(M \geq 5.0)$ that filled a space that was relatively quiet before the Kumamoto Earthquake. Their focal mechanisms are shown in Fig. 1 within subregion (SR4) near Mt. Kuju. The strike and dip angle of the deeper (about $10 \mathrm{~km}$ ) event were $220^{\circ}$ and $72^{\circ}$, respectively. The strike and dip angle of the shallower (about $8 \mathrm{~km}$ ) event were $314^{\circ}$ and $86^{\circ}$, respectively. By comparing these focal mechanisms to seismicity around this area, it was clear that seismicity is concentrated on their nodal planes. 


\section{Beppu-Haneyama fault zone}

A cluster of seismicity at the western bound of the Beppu-Haneyama fault zone formed a NW-SE-trending line of about $10 \mathrm{~km}$ (marked "f" and with arrows in the map in Fig. 4). For events in this NW-SE-trending cluster have the direction of $P$ axis as NE-SW dominantly. In spite of its distribution of seismicity being NW-SE trending, which is different from overall trending as $\mathrm{E}-\mathrm{W}$ direction, $T$ axis orientation is generally consistent with the surrounding shown in Additional file 5: Figure S3. Normal and strike-slip types of focal mechanisms within this NW-SW-trending cluster are dominated as well as its surrounding. In addition, these characteristics of focal mechanisms for this area during the Kumamoto Earthquake sequences are consistent with Terakawa and Matsu (2010). The cross sections along the lines " $M$ " and "N" show that this new cluster seems to fill a gap in past seismicity (Fig. 4). Such small clusters made up with an overall seismicity pattern with a NE-SW-trending line parallel to the direction between the Yufu and Tsurumi volcanoes (arrow "g" in Fig. 4). This linear pattern has now been clearly seen for about $25 \mathrm{~km}$. The dominant focal mechanisms, normal type and NE-SW trend, agree with the characteristics of the Beppu-Haneyama fault zone rather than with an individual NW-SE trend (Additional file 5: Figure S3).

\section{Conclusions}

We have relocated hypocenters that occurred during the Kumamoto Earthquake sequence using a double-difference method, incorporating cross-correlation differential times as well as catalog differential times to provide highresolution earthquake locations. The relocation results are compared with background seismicity for 12 years from 2001 to 2012 (JUICE catalog, Yano et al. 2017). The background seismicity events from this study were also relocated using a double-difference method.

The two largest events (M6.5 on April 14, 2016, and M7.3 on April 16, 2016) occurred in a complicated region where the Hinagu and Futagawa faults meet. This area has been experienced events up to about $M 7$ historically. We compared three different periods, (P1) background seismicity (from JUICE catalog), (P2) between M6.5 and M7.3 event, and (P3) after M7.3 event until August 31, 2016. Background seismicity in the period P1 lies along the Beppu-Shimabara graben including the Hinagu fault zone, Futagawa fault zone, Aso area, and the BeppuHaneyama fault zone. Our results show that seismicity during the period P2 aligns linearly along the northern part of the Hinagu fault zone called the Takano-Shirahata region. The seismicity during the period P3 aligns along the Beppu-Shimabara graben including the Hinagu fault zone, Futagawa fault, the north of the Aso caldera, and Beppu-Haneyama fault zone. Aftershocks during both periods P2 and P3 generally occurred within the site of background seismicity.

High-resolution earthquake locations allowed us to find not only a seismicity sequence of the 2016 Kumamoto Earthquake within the background seismicity, but also some clusters of events that occurred in small regions where the background seismicity has not yet been confirmed. These new seismic areas are apparent along the northern boundary of the Aso caldera and the Beppu-Haneyama fault zone. The new seismicity within the Beppu-Haneyama fault zone, in particular, helps shape a clear line parallel to the direction between the Yufu and Tsurumi volcanoes.

A low-seismicity region became apparent on the northwest of the Aso caldera after the M7.3 event. This area had not been prominent due to its moderate seismicity prior to the $M 7.3$ event. The low-seismicity region separates seismicity into two zones between the Futagawa fault and the Aso area. The events that occurred, west of (the Futagawa fault) and east of (the Aso area) the low-seismicity region, have different types of focal mechanism as well as dip angles, according to the F-net CMT solutions and our results.

\section{Additional files}

Additional file 1: Figure S4. b-value estimates before and during the Kumamoto sequence along the Futagawa fault. Top panel is a map showing the region estimated its $b$-value. Middle and bottom panels show that histograms of seismicity, b-values, a-values, and standard deviations of $b$ and a-values for background (middle panel) and during the Kumamoto earthquake sequences (bottom).

Additional file 2: Table S1. HypoDD iteration and weighting parameters used in this study.

Additional file 3: Figure S2. Histogram showing distribution of standard deviation of the difference from the hypocenter depth of our final result to the depth relocated due to 100 different velocity models in region (SR2). Top panel is the background seismicity (JUICE catalog) and bottom panel is the seismicity of aftershocks. This test implies that the hypocenter can be located its depth about $1 \mathrm{~km}$ in error due to an incorrect velocity structure. In other words, it is less likely that the hypocenter depth is more than $5 \mathrm{~km}$ apart from the final result because of the velocity structure. The 100 models of velocity structure are generated by changing the moho depth from $10 \mathrm{~km}$ to $40 \mathrm{~km}$ from the original velocity model (Ukawa et al. 1984).

Additional file 4: Figure S5. Explanation: our definition of seismic "calm" region.

Additional file 5: Figure S3. T-axis orientation and rose diagram of normal, reverse, and strike type of hypocenters from Hi-net first motion solution (2016/4/14-2016/5/20) in Oita region (SR5). Beachballs in green, blue, and red indicate their type of event such as strike, normal, and reverse, respectively.

\section{Authors' contributions}

TY and MM designed this study. TY and MM analyzed the data. TY and MM drafted the manuscript. All authors contributed equally toward managing the observations. Both authors read and approved the final manuscript. 


\section{Acknowledgements}

Data for this study come from Japan Meteorological Agency (JMA), Kyushu University, and Kagoshima University as well as National Research Institute for Earth Science and Disaster Resilience (NIED). We also acknowledge that all of the maps were created using the GMT (Generic Mapping Tools) software package. We would like to thank the anonymous reviewers for their helpful and constructive comments that greatly contributed to improving the letter. We would also like to thank the Editor, Takuya Nishimura, for their generous comments and support during the review process.

\section{Competing interests}

The authors declare that they have no competing interests.

\section{Publisher's Note}

Springer Nature remains neutral with regard to jurisdictional claims in published maps and institutional affiliations.

Received: 10 August 2016 Accepted: 16 May 2017

Published online: 30 May 2017

\section{References}

Fitch TJ (1972) Plate convergence, transcurrent faults, and internal deformation adjacent to Southeast Asia and the Western Pacific. J Geophys Res Solid Earth 77:4432-4460. doi:10.1029/JB077i023p04432

Kamata H, Kodama K (1994) Tectonics of an arc-arc junction: an example from Kyushu Island at the junction of the Southwest Japan Arc and the Ryukyu Arc. Tectonophysics 233:69-81

Kubo H, Suzuki W, Aoi S, Sekiguchi H (2016) Source rupture processes of the 2016 Kumamoto, Japan, earthquakes estimated from strong-motion waveforms. Earth Planets Space 68:161. doi:10.1186/s40623-016-0536-8

Matsubara M, Obara K (2011) The 2011 off the Pacific coast of Tohoku Earthquake related to a strong velocity gradient with the Pacific plate. Earth Planets Space 63:663-667. doi:10.5047/eps.2011.05.018

Matsuda T (1973) The Median Tectonic Line as an active strike-slip fault system. In: Median Tectonic Line. Tokai University Press, pp 239-251

Matsumoto S, Nakao S, Ohkura T et al (2015) Spatial heterogeneities in tectonic stress in Kyushu, Japan and their relation to a major shear zone. Earth Planets Space 67:172. doi:10.1186/s40623-015-0342-8
Matsumoto N, Hiramatsu Y, Sawada A (2016) Continuity, segmentation and faulting type of active fault zones of the 2016 Kumamoto earthquake inferred from analyses of a gravity gradient tensor. Earth Planets Space 68:167. doi:10.1186/s40623-016-0541-y

Obara K, Ito Y (2005) Very low frequency earthquakes excited by the 2004 off Kii peninsula earthquakes: a dynamic deformation process in the large accretionary prism. Earth Planets Space 57:321-326. doi:10.1186/ BF03352570

Okada Y, Kasahara K, Hori S et al (2004) Recent progress of seismic observation networks in Japan-Hi-net, F-net, K-net and KiK-net. Earth Planets Space 56:XV-Xxviii. doi:10.1186/BF03353076

Prejean S (2002) Fault structure and kinematics of the Long Valley Caldera region, California, revealed by high-accuracy earthquake hypocenters and focal mechanism stress inversions. J Geophys Res 107:1-19. doi:10.1 029/2001JB001168

Research Group for Active Faults of Japan (RGAFJ) (1991) Active faults in Japan. University Tokyo Press, Tokyo

Seno T, Stein S, Gripp AE (1993) A model for the motion of the Philippine Sea plate consistent with NUVEL-1 and geological data. J Geophys Res 98:941-948. doi:10.1029/93JB00782

Terakawa T, Matsu M (2010) The 3-D tectonic stress fields in and around Japan inverted from centroid moment tensor data of seismic events. Tectonics 29:1-14. doi:10.1029/2009TC002626

The Headquarters for Earthquake Research Promotion (2013) The long-term evaluation of the active faults in Kyushu region. http://www.jishin.go.jp/ main/chousa/13feb_chi_kyushu/k_honbun.pdf. Accessed 10 July 2016

The Headquarters for Earthquake Research Promotion (2016) Evaluation of the 2016 Kumamoto earthquake. http://www.static.jishin.go.jp/resource/ monthly/2016/2016_kumamoto_3.pdf. Accessed 10 July 2016

Ukawa M, Ishida M, Matsumura S, Kasahara K (1984) Hypocenter determination method of the Kanto-Tokai observational network for microearthquakes. Res Notes Natl Res Cent Disaster Prev 53:1-88

Waldhauser F, Ellsworth WL (2000) A double-difference earthquake location algorithm: method and application to the northern Hayward fault, California. Bull Seismol Soc Am 90:1353-1368. doi:10.1785/0120000006

Yano TE, Takeda T, Matsubara M, Shiomi K (2017) Japan unified highresolution relocated catalog for earthquakes (JUICE): crustal seismicity beneath the Japanese Islands. Tectonophysics 702:19-28. doi:10.1016/j. tecto.2017.02.017

\section{Submit your manuscript to a SpringerOpen ${ }^{\circ}$ journal and benefit from:}

- Convenient online submission

- Rigorous peer review

- Immediate publication on acceptance

- Open access: articles freely available online

- High visibility within the field

- Retaining the copyright to your article

Submit your next manuscript at springeropen.com 